\title{
INTEGRACIÓN REGIONAL Y MUNIDIALIZACIÓN
}

Ing Roberto Meza

Ensayista, Politico, Diplomático y Analista

E I cambio constante parece ser el de nominador común de la civiliza ción global que nos toca vivir, por eso, los paises que consideran su realidad interna como inamovible son incapaces de asimilar los cambios, para cllos, los c,ambios son algo irracional. Cada vez mas, la gente considera .1 cambio no como algo yue enriquece su liberad y su dignidad. sino como una fuerza que promueve la avaricia y la injusticia. Al concentrar tanco la riqueza. -el fenómeno conocido como Globalización y que a otros nos gusta llamar Mundialización- produce mas amenazas que oportunidades. I as dificultades para transferir conocimientos y nuevas tecnologias del centro a la periferia, por cjemplo, amplia las desigualdades económicas y someten a algunos palses a nuevas formas de colonialismo. Conscientes del fenómeno, muchos creen y de hecho opinan, que una nueva clase dominance manipula la mundialización para su propio beneficio.

Al limitar las perspecrivas de crecimiento para tanta gente, el orden económico actual es inconsistente con los ideales de la revolución democrática de fines del Siglo XX. la cual afirma que nadic debe quedarse atrás. Para nucstros pueblos que ahora están marginados del proceso de desarrollo tecnológico, creo que sólo cxiste una opción viable: una nueva a irmación de sí mismos como Estados independientes integrados regionalmente en codas las formas que les sea posible.

Sólo con la libertad se da la confianza para una mayor participación, lo cual se traduce en una mejor gobernabilidad. tanto en el orden internacional como al interior de los Esrados. La ingobernabilidad surge de los marginados o excluidos socialmente que no pucden parcicipar en las decisiones que decerminan sus vidas cotidianas. Tanto ciudadanos como Estados se vuelven ingobernables cuando las decisiones las roma una élite cerrada que gobierma transformando al resro en una masa mudi.

Los ciudadanos libres, los Esrados libres. son los verdaderos arquirecros de la gobernabilidad. Sin una responsabilidad plena e igual, no existe la gobernabilidad duradera.
Eso es lo que los fundanentalistas del mercado. los asesores financieros, $n$ la los tecnócrat.as, logran entender. No se puede excluir a paises, ciudadianos, consumidores, productores, empresarios, obreros y profesionales, de la roma de decisiones que tienen consecuencias sustanciales sobresus vidas e incluso sobre los valores mismos de la socied.ad.

La gente en las democracias consolidadas reconoce que el sistem.1 democrático ha mejorado la prosperidad. Nosotros, en América Latina, sabemos que la democracia tiene problemas para poder vivir en medio de las crisis, pobrezay aislamienero. Prescrvar los valores democr. ícos es dificil cuando existen secrores muy unplios que no se pueden integr.ur al mercado global, cuindo la miseria acaba con la dignidad humana y cuando la falta de opciones hace que la liberead pierda su significado.

En los Estados, individu.slmente considerados, la protección al débil sc logra con la aplicación igual de la ley. csto falta volverlo realidad en las relaciones internacionales. Pro par. crear un orden internacional bas. Ido en la ley y no en la fuerz.ı. ahora que la fuct a económica ha desplizado al poderio militar, es necesario reforzar el multilateralismo y extenderlo no sólo cn lo cconómico sino t.mbién en lo polícico.

['orque en esos Estados el conjunto de procesos y prícticas que reconocemos como mundialización no han sido acontecimientos casuales, ni producto de la fatalidad económic. o tecnológica. Son el resultado de una serie de deciviones y acciones cuyo objetivo es l. creación de un espacio iniro. donde pueden circular. sin limit.ación alguna, bienes, servicios. $y$ sobre todo el dinero. converi- do ast en la mereaderia pror excelencia. Este enorme mercado global. que ha sido posible: por el desarrollo de las nuevas tecnologias, en particular de la icleinformación, debc, sin cmb.argo. su existencia, a la convergencia de lus intereser de las enipresas tr.insnacionales y de la politica conómica de los tiados Ĺndos. y de los oures grondes listados desarrollados del hemislicro Nortc. Sus instrumentes han sido l. ideologia ultraliberal y los organismos econónicos intergubernament.ales: 1:AIl, Banco Mundial, (OMC y la OCD): Por oura parte, la liberalización de todo upo de intercambios y la supresión de cualquier marco juridico susceptible de regul.ırlos, forman su doctrina y en ellas asient.an su funcionamiento.

Estc nuevo orden cconómico mundial, que privilegia el paradignia fin.nnciero $y$ la especulación sobre la inversión, produce consecuenci.ss negativas. Por eso. pretender que el b.lance actual de l. m mundialización es positivo, no es mís que una interesada filsedad. $Y_{d}$ que, si por una parte, el crecimiento mundial en 1999 ha sido de casiel $3.5 \%$, por orra, se ha 
acelerado la degradación del medio ambiente, ha aumentado la concentración de la riqueza y in creación de oligopolios, se ha reducido la seguridad en el consumo de alimentos, se han agravado las desigualdades hacia el interior de los Estrados, se ha generalizado la criminalidad organizada. la uniformación cultural y parece no tener limites la miseria y cl hambre, que han alcanzado cous insoportables. Estas dramáricas consideraciones no proceden de la pluma de algún extremista, lo ha escrito Michel Camdessus, en cu.ınto dejóla Presidencia del Fondo Monecario Internacional y nos lo han recordado también. los líderes máximos en las últimas rcuniones del G-7 y del Banco Mundial.

Pretender reordenar este calculado desorden es trabajo inútil. Por ello, insisto, hay que intentat crear una estrategia coherente para enfrentarlo. ¿Cómo? Desde dentro de si mis$\mathrm{ma}$, desde el interiorde su propio proceso pues su impugnación retórica lejos de debilitarla la forralece. Puesto que de nada sirve la defensa basada en la soberania de los Estados-Nación del Siglo XIX, ya que encerrada en sus propios muros, sus planteamientos tienen poco que decir. Porque no se trata de negar la mundialización, sino de asumirla. desconstruyéndola para poder reconstruirla desde una opción de progreso. Los principales protagonistas de esa desconstrucción están inregrados a la lucha agrupados en el International Forum on Globalization (IFG). y en el Foro Social Mundial. Estas agrupaciones disputan el terreno a las multinacionales y no se conforman con pequerios parches sociales, sino que, apoyadas en la sensibilidad y la conciencia solidaria, cada día más extendidas, apuntan a otra mundialidad. Tal internacional civil, de membresía dispar y a veces hasta contradictoria, nace a la luz pública en Seatrle y se conscituye en una punta de lanza de la oposición a los grupos gestores de la mundialización liberal: FMI, Banco Mundial, OMC, OCDE. Pero la figura contestataria que esa oposición conciene, oculta la ausencia de propuestas y prácricas sólidas, que, más allá de la anulación de la deuda a los paises más pobres y del fin de los ajustes estructurales, propone el control democrático de la gobernación del mundo y una mundialización alternativa presidida por la solidaridad.

Ahora bien, junto a ese trabajo ciudadano popular, cabe una acción social institucionalizada como deciamos antes, cuya vía mís prácrica parece ser la creación de mulritud de polos mundiales, es decir, la segmen- tación en espacios interrelacionados y que estos sean autónomos. Me refiero al nacimiento de áreas unificadas de la misma naturaleza cultural, asl como política y económicamente estructuradas, cal como lo vive la Unión Europea yue es el ejemplo más logrado.

La necesidad de crear o promover otras macroáreas, encre cllas la que representa América Central, que a pesar de los grandes obstáculos con que tropieza su integración, ha constiruido desde su independencia, un permanente proyecto común. Proyecto común que ha generado diversos procesos de institucionalización global de desigual fortuna, pero que si ha contribuido a definir las condiciones para acabar lográndolo. El lanzamiento de! Mercado Común Centroamericano de 1960. la Insticucionalización del Parlamento y la Corte Centroamericana de Justicia, así como la fundación de la Secrecaria Permanente (SICA) han puesto de relicve la voluntad, $y$ 'al mismo ciempo, las dificultades, de agrupar al conjunto de paises centro.tmericanos, aunque sea limitándose en un primer momento a establecer foros de entendimiento común.

I) aquí nace el convencimiento de que hay que proceder subregionalmente $y$ paso a paso. Lo que no acaba de suceder por la prevalencia de los intereses nacionales más coyunturales e inmediatos y por la ausencia de una voluntad política integradora. Dada la dificultad de transformar a los parcidos y políticos nacionales en partidos de una nueva área común, porquetodos temen que la transformación los derribe del caballo, sólo se puede contar con los actores de las sociedades civiles de los paises involucrados.

En cllas, y atendiendo al ámbito económico, que es el más inmediato, los primeros actores a tomar en cuenta deben ser los pequeńos y medianos empresarios que constantemente están contribuyendo al crecimiento de los intercambios regionales. El balance de la experiencia con todas las dificultades ha sido muy positivo y el mayor impedimento con que sigue tropezando es la falta de un mecanismo eficiente que resuelva los litigios comerciales. véase sí no, la crema, el queso y los pollos. La creación de una instancia de arbitraje, flexible $y$ diversificada por sectores $y$ materias, promovida y apoyada por los Presidentes de las Cortes Supremas, puede ser una herramienta que. $\sin$ las precensiones ni las suspicacias que suscita cl Tribunal Supremo común, que tiene su sede en Managua, resultaria muy cficaz.
Esto me lleva a considerar a otro de los grandes protagonistas del Menado Común, los profesionales de la Justicia y el Denecho, sobrerodo los Jueces y los abogados que son determi nantes para el destino, de la integración. Porque hay que docar de reglas al Mercomún y aplicarlas, ya que un mercado sin reglas se vuelve un mercado de mafias.

En resumen, para desmontar esta mundialización salvaje y monopolista, lo primero es reducir la dominación del espacio global, único y desregulado, mediante un conjunto de macromercados que hagan posible funcionar a las distintas comunidades territoriales y sociales de cada área. Pero esta fase preliminar no basta. Hay que acometer al mismo riempo el alumbramiento de la otra mundialización. Porque no se trata de humanizat la mercantilización del mundo compasivamente, pues compasión no es una respuesta política, sino de gestar una ciudadania democrácica. Pues sólo un mundo de ciudadanos compromeridos con la democracia puede producir una mundialización solidaria.

Como no se puede revertir la tendencia globalizidora, según ha quedado demostrado cn las páginas anteriores, hay que aceptar el desafio y aprender rápidamente el conocimiento y la tecnología de punta. Para ello es esencial cambiar los sistemas educativos con orientación hacia la mejora de los procesos productivos, en donde un mayor saber le dotará al ser humano de mejores ingresos, y con esto retendremos a los talentos nacionales que se fugan del pais para trabajar en los paises desarrollados, porque la emigración no sólo es de mano de obra sino también de médicos, ingenieros y profesores que buscan lejos de nuestro pais un mejor salario. En este aspecto, bien lo sabemos, se está produciendo también una globalización, alentada por motivos foráneos de atracción a nuestros calentos.

La mundialización también implica la operación libre de las tr ansnacionales en todos los ámbitos del quehacer económico, ya ahora encontramos fábricas que son vendidas a las transnacionsles, cuando la política debería ser más bienque las empresas del ára se posicionen mcjor en nuestros mercados, para enfrentar a los foráneos que vienen a desplazarnos de los buenos negocios. Entonces la mundialización no sólo se queda en la privarización de las Empresas de servicios públicos, sino rambién en la compra de limpresas nacionales, en cuyo caso sólo funciona el afón de lucro y soslaya las consideraciones del apego a un pais, a un territorio. a una sociedad o a una patria. 